\author{
Volodymyr Skorokhoda, Yuriy M elnyk, Natalia Semenyuk \\ and Oleh Suberlyak

\section{OBTAINING PECULIARITIES AND PROPERTIES OF POLYVINYLPYRROLIDONE COPOLYMERS WITH HYDROPHOBIC VINYL MONOMERS}

\author{
Lviv Polytechnic National University, \\ 12, S. Bandera str., 79013 Lviv, Ukraine; vskorohoda@yahoo.com
}

Received: January 20, 2014 / Revised: February 12, 2014 / Accepted: M ay 30, 2014

(C) Skorokhoda V., Melnyk Y., Semenyuk N., Suberlyak O., 2015

\begin{abstract}
Polymerization of hydrophobic vinyl monomers in polyvinylpyrrolidone aqueous solutions has been investigated under ultrasonic treatment. The effect of ultrasound on the destruction of water-soluble polymeric matrices has been examined. The obtaining mechanism of block- and grafted copolymers of vinyl monomers with polyvinylpyrrolidone has been proposed. The copolymers have been synthesized as films and their main properties, physico-mechanical and sorption-diffusive, in particular, have been investigated.
\end{abstract}

Keywords: polyvinylpyrrolidone, film coating, destruction, ultrasound, block copolymer, penetration.

\section{Introduction}

The polymers synthesis and modification via monomers polymerization in the presence of polymeric matrices are intensively developed in chemistry and chemical technology of high-molecular compounds. Polyvinylpyrrolidone (PVP) as a matrix is of great scientific and practical interest due to the effective application of copolymers on its basis in medical, biological and pharmaceutical industries. Crosslinked and non-crosslinked PVP copolymers are used for the production of corrective contact lenses, (hemo)dialysis membranes, implants, leather substitutes, systems of drugs controlled release, etc. [1, 2]. Less attention is devoted to the investigations of matrix polymerization over polyvinylpyrrolidone of the monomers which do not solve PVP and do not form homogeneous solutions with them. Therefore the development of PVP new copolymers and effective ways of their production is a key point for science and industry.
Last decades in industry the ultrasonic energy (acoustic vibrations with the frequency of $2 \cdot 10^{4} \mathrm{~Hz}$ ) is used to intensify many technological processes [3]. While propagating vibrations in the liquid phase they cause a series of specific effects, such as ultrasonic cavitation, luminescence excitation, initiation of chemical reactions, etc. Under the action of ultrasound (US) the effect of temperature and oxygen on the chemical reactions differs from the traditional influence and the reactions proceed with high rates even at low temperatures. So, the interest in studying and development of polymerization processes in the US field is understandable because it supposes the simplification of the synthesis technology. Moreover, we may expect the additional properties of polymers which are not characteristic for them. In particular, it is foreseen that polymerization of hydrophobic monomers under US treatment in the presence of PVP would allow to give hydrophilic properties and film-forming ability to the polymers on their basis. However the mechanism complexity of US action does not allow to create the unique theory which clearly explains phenomena occurring in US field. Therefore it is necessary to investigate US effect on the structure and properties of synthesized products for each specific case.

The aim of the present work is to study the polymerization of hydrophobic vinyl monomers in PVP aqueous solutions under US treatment, to form film coatings on their basis and to examine the film main properties.

\section{Experimental}

Before the experiments methcrylate (MA) and butacrylate (BA) produced by Bisomer were washed by $5 \%$-solution of $\mathrm{Na}_{2} \mathrm{CO}_{3}$, dried by $\mathrm{Na}_{2} \mathrm{SO}_{4}$ and $\mathrm{Na}_{2} \mathrm{O}$ 
zeolite and then purified by double distillation (fir-tree refluxer; hydroquinone as an inhibitor). Styrene was washed by $5 \%$-solution of $\mathrm{NaHSO}_{3}, 10 \%$-solution of $\mathrm{NaOH}$, and distilled water; then dried by $\mathrm{CaCl}_{2}$ and zeolite $\mathrm{Na}_{2} \mathrm{O}$; then distilled under vacuum (residual pressure of $5.3 \mathrm{kPa}, T=333 \mathrm{~K}$, hydroquinone as an inhibitor). High-purified PVP produced by AppliChem $\mathrm{GmbH}$ was used. The polymerization kinetics was studied in accordance with the changes of unreacted monomer amount [4].

Ultrasonic investigations were carried out using Ultrasonic disintegrator UD-20 automatic (frequency $20 \mathrm{kHz}$, intensity $5 \cdot 10^{4} \mathrm{~W} / \mathrm{m}^{2}$ ) with cylindrical magnetostrictor. The ratio between its diameter and reactor diameter is 0.5 . The reactor equipped by thermostatic jacket is made of X18H9T stainless steel and has a volume of $100 \mathrm{ml}$. The volume of experimental sample is $40 \mathrm{ml}$. The films were formed by emulsion pouring over glass plate followed by a solvent evaporation.

The film mechanical properties were determined in accordance with standards using Kimura Machinery tensile-testing machine of $0.50 /$ RT-6010 type. The polymers molecular weight was determined using viscosimeter VPG-2 at $293 \mathrm{~K}$. The polymers water content was determined by a mass method. The diffusion penetrability of the films for water and soluble compounds in it was determined without external pressure using a laboratory osmometer according to the procedure suggested by F. Karelin [5].

\section{Results and Discussion}

Since the polymerization is carried out in the ultrasonic field, the investigations of its influence on the components of the reaction mixture, and first of all, on the polymeric matrices, are of great interest. It may be foreseen from the literature $[3,6]$ that polymeric matrices undergo destruction accompanied by the decrease of molecular weight and formation of radicals. The latter may be used as active factors for the further graft- or block-copolymerization.

The ultrasonic treatment of PVP solution (MW $300 \cdot 10^{3}$ ) decreases its molecular weight (Fig. 1). The obtained curves are similar to those of polymers mechanic destruction: the molecular weight decreases by the definite value and then remains constant. The most intensive destruction takes place for the first 10-20 min.

PVP susceptibility to the destruction under US is diminished with the decrease of the molecular weight (Fig. 1). PVP with MW of 28000 and 12000 is not changed even after US-treatment for $30 \mathrm{~min}$. The same result is obtained for the polymeric matrix PEG-115.
Retardation of macromolecule destruction after the achievement of definite molecular weight, as well as less susceptibility to the ultrasonic destruction of polymers with small molecular weight may be explained as follows. Since the total energy of weak physical interactions between macromolecule links is often greater than the energy of chemical bond in the main chain, the ultrasonic vibrations evidently cause the weaker bond cleavage and formation of two macroradicals. Such effect of US destruction is observed till the moment when the total energy of physical intramolecular interactions of the macromolecule chain links would be equal to the energy of chemical bonds in the chain. Then the dispersion processes are predominantly observed.

The nature of medium, where polymeric matrix is solved, slightly affects the rate and depth of the destruction, though there is some decrease in the destruction rate for the investigated solvents: butanolwater-dimethylsulfoxide (Fig. 1, curves 1-3).

The obtained results allow to determine the effect of ultrasound on the polymeric matrices in the solution and further are used to explain the results of polymerization kinetics.

The polymerization under US treatment was studied at ratio polymer solution : monomer equal to $7: 1$ $(\mathrm{v} / \mathrm{v})$. All investigated monomers are polymerized in the presence of PVP under US treatment without induction period (Fig. 2). Moreover, the polymerization rate increases in the row butylacrylate < methylacrylate $<$ styrene. For styrene the polymer yield exceeds $80 \%$ already after $30 \mathrm{~min}$ from the reaction beginning.

The highest reaction ability of styrene is caused by its highest hydrophobicity. The most stiff and non-mobile polymeric chains of polystyrene, as well as the most indicative phase boundary (monomer - PVP aqueous solution) are formed on the basis of styrene. It is also necessary to take into account that in the most hydrophobic systems PVP shows the highest adsorptive activity on the phase boundary [7]. Such boundary favors the monomer solvation on PVP links and complex formation with transfer of charge which is polymerization activator [7]. The active role of phase boundary for the polymerization under US treatment is confirmed by the fact that polymerization of methacrylate with the concentration of $0.4 \mathrm{~mol} / \mathrm{dm}^{3}$ (the maximum concentration under which the homogeneous system is formed) proceeds slower than that with the concentration of $1 \mathrm{~mol} / \mathrm{l}^{3}$ (concentration under which the clear phase boundary monomer-PVP aqueous solution is observed; Fig. 2).

The effect of PVP amount in the aqueous phase on the polymerization rate becomes apparent at low concentrations and has extreme character with the 
maximum at PVP concentration of $1 \mathrm{wt} \%$ (Fig. 3). The obtained results are in good agreement with previous investigations about the effect of PVP concentrations in the aqueous phase on interphase polymerization of vinyl monomers [8]. PVP optimum concentrations are $0.5-3$ wt $\%$ taking into account the possibility of directed change of the polymerization rate.

The polymerization rate considerably depends on nature and molecular weight of polymeric matrix (Fig. 4). The lowest polymerization rate is typical for the composition with PVP of the highest molecular weight $\left(44 \cdot 10^{3}\right)$. There is a clear dependence - the process rate

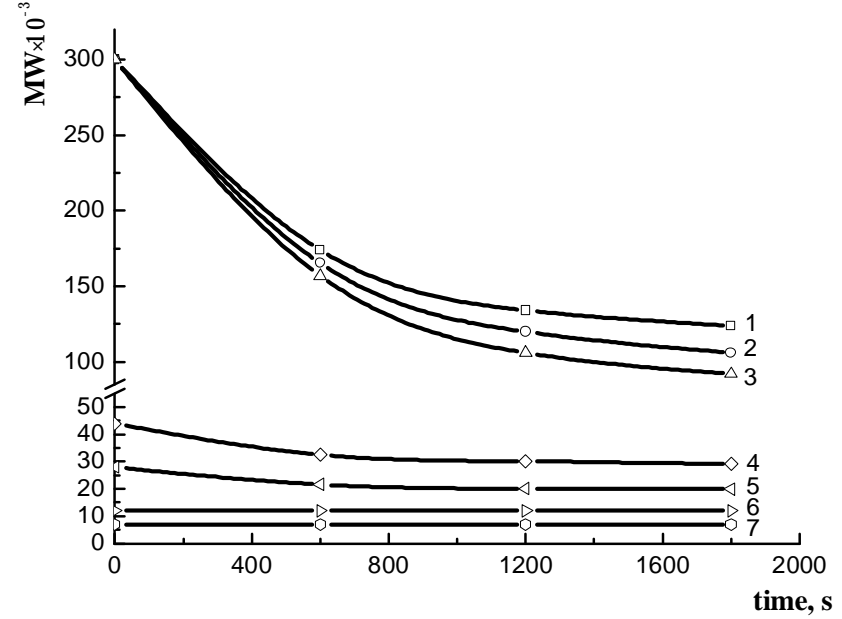

Fig. 1. Change in the molecular weight of the polymeric matrix under US treatment. Polymers: PVP $(1-3,5,6)$ and polyethylene glycol PEG (7). Molecular weight $\left(\mathrm{MW} \cdot 10^{-3}\right): 300$ (1-3); 44 (4); 28 (5) and 12 (6). Solvents: dimethylsulfoxide (1); water (2, 4-7) and butanol (3)

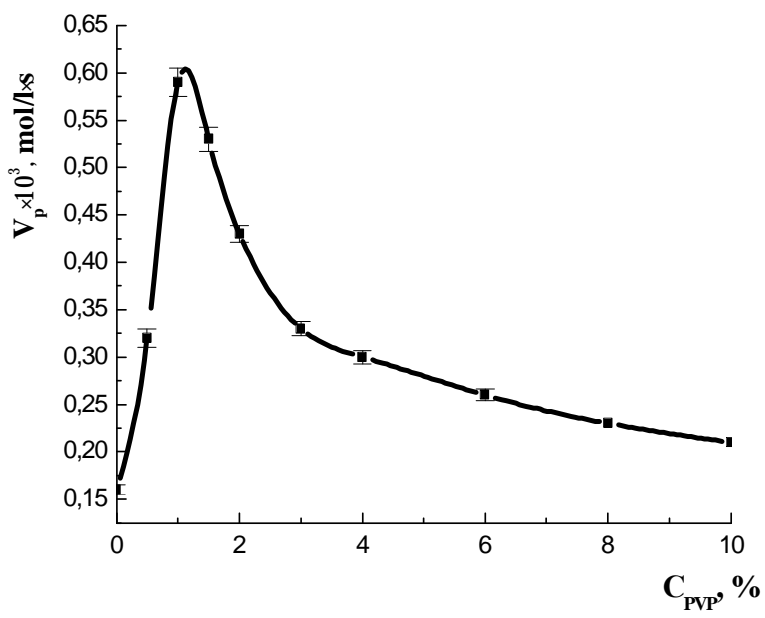

Fig. 3. Dependence of styrene polymerization rate on PVP concentration. $T=293 \mathrm{~K} ; C_{m}=1 \mathrm{~mol} / \mathrm{l} ; \mathrm{MW}_{\mathrm{PVP}}=28 \cdot 10^{3}$ decreases with the increase of PVP molecular weight. This fact is also in agreement with the investigation results of interphase polymerization of vinyl monomers in the presence of PVP [9]. The authors substantiate such phenomenon by the increased viscosity of PVP aqueous solutions and change of energetic characteristics of phase boundary.

On the other hand, the considerable effect on the process kinetics has the nature of polymeric matrix as well. PEG and PVP are close by their molecular weights $\left(\mathrm{MW}_{\mathrm{PEG}}=7 \cdot 10^{3}\right.$ and $\left.\mathrm{MW}_{\mathrm{PVP}}=12 \cdot 10^{3}\right)$ but essentially differ by their influence on the polymerization rate.

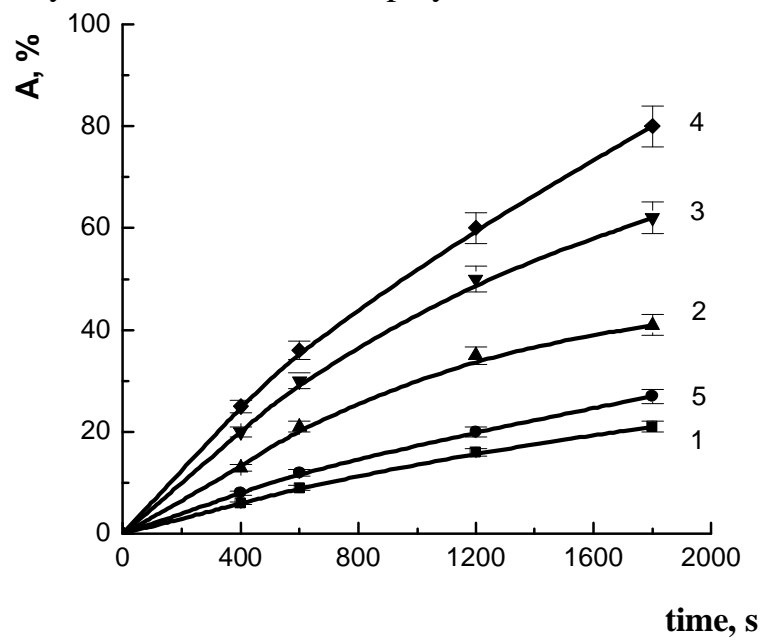

Fig. 2. Polymer yield (A) vs. monomer nature. Monomers: butylacrylate $(1)$; methylacrylate $(2,3)$ and styrene $(4,5)$. Concentrations (mol/l): 1 (1, 3-5) and 0.4 (2). PVP content (\%): $1(1-4)$ and 0 (5). $\mathrm{MW}_{\mathrm{PVP}}=28 \cdot 10^{3} . T=293 \mathrm{~K}$

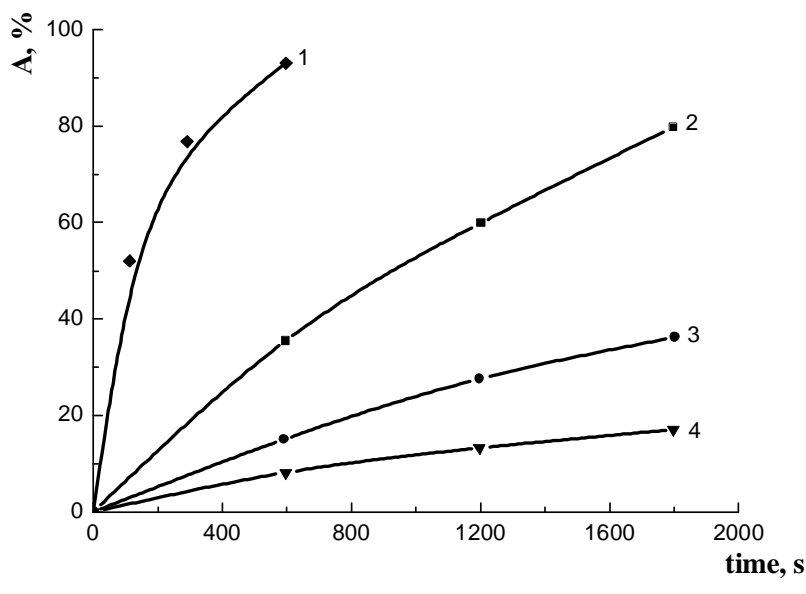

Fig. 4. Effect of nature and molecular weight of polymeric matrix (PM) on polystyrene yield. Polymeric matrix: PVP (13 ) and PEG (4). $\mathrm{MW}_{\mathrm{PVP}} \cdot 10^{-3}: 12(1) ; 28$ (2) and 44 (3). $T=293 \mathrm{~K} ; C_{P M}=1 \% ; C_{m}=1 \mathrm{~mol} / \mathrm{l} ; I=5 \cdot 10^{4} \mathrm{~W} / \mathrm{m}^{2}$ 
While analyzing the reaction chemism in US field it is necessary to take into account the complex effect of several factors. The main factors are intramolecular interaction between monomer molecules and segments of PVP macromolecules on the phase boundary and dispersive action of ultrasound. The latter shows itself in both activation of polymeric system components and strengthening of interphase interactions.

Due to the action of high energies occurring during cavitation in US field, cleavage of monomer $\pi$-bond takes place first of all. It should be noted that $\mathrm{H}^{\bullet}$ and ${ }^{\circ} \mathrm{OH}$ radicals (products of water dissociation $[3,6]$ ) which are present in the solution may interact with PVP macromolecule and form macroradicals with the active center in the middle of macromolecule:

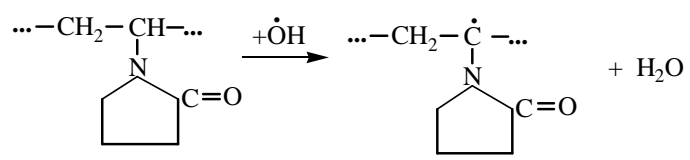

The formed macroradicals may recombine with the growth chains and form grafted copolymer.

It is logically to assume the participation of formed PVP macroradicals in the initiation of vinyl monomers polymerization. However, it is obvious from Fig. 4 that the slowest polymerization occurs while using PVP which is destructed in the deepest way. The most effective polymerization is typical of low-molecular PVP which is poorly destructed in US field. Thus we may assert that PVP macroradicals formed due to the ultrasonic destruction are not determinants for the polymerization initiation. It is obvious that their main part participate in the reactions of chain break and transfer. But their recombination with radicals which are formed during water dissociation is the most probable reaction:

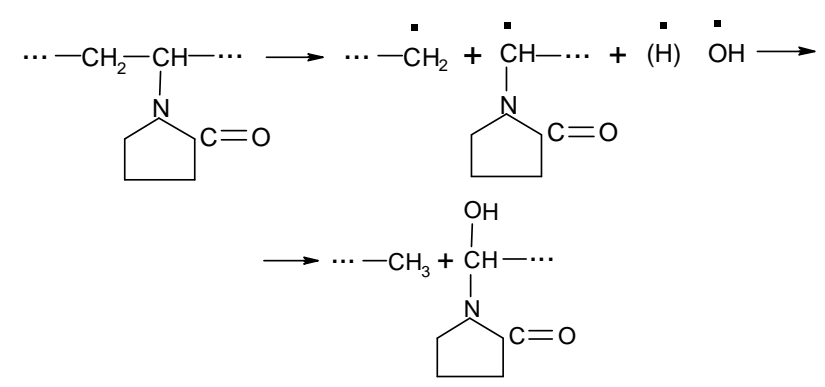

Taking into account that the reaction occurs on the phase boundary we may assume that high dispersity of the emulsion formed under US action is one of the main reasons of reaction intensification. It is known [9] that the increase of phase boundary surface increases the rate of radical reactions. In this case it is achieved due to the increase of dispersion.

Along with homopolymerization initiation under US the macroradicals of two types are formed due to the macromolecules decomposition under the influence of cavitation energy released in the ultrasonic field:

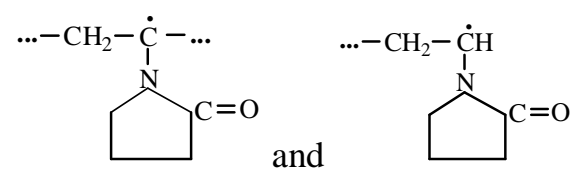

During their interaction with vinyl monomers $\mathrm{CH}_{2}=\mathrm{CHR}$ the radicals may form grafted<smiles>[R]C([R])CC(C)(CC([R])C)N1CCCC1=O</smiles>

and block copolymers:<smiles>[R]C(C)CC([R])CC(CC)N1CCCC1=O</smiles>

The copolymers formation is confirmed by IRspectroscopy. The absorption bands typical of PVP are present at $650,1275,1415$ and $1480 \mathrm{~cm}^{-1}$ in IR-spectrum of copolymer extracted by water-ethanol solution to remove homopolymer (PVP).

The emulsions synthesized under US are characterized by high sedimentation stability and good film-forming properties. On the basis of emulsions, experimental films were obtained by a pouring method on a glass baseplate, followed by evaporation of the solvent. The emulsions were prepared on the basis of PVP aqueous solutions and hydrophobic monomers (MA, styrene). The treatment time was determined based on the investigation results of the polymerization kinetics under US intensity of $5 \cdot 10^{4} \mathrm{~W} / \mathrm{m}^{2}$. For the compositions based on styrene it was $40 \mathrm{~min}$ and for those based on MA - $60 \mathrm{~min}$.

For the obtained films we determined solubility, thermo-physical and physico-mechanical properties. The investigated copolymers are soluble in chloroform, benzene, toluene and partially in cyclohexanol that means the absence of crosslinked fraction. This fact also confirms the formation of non-crosslinked block- and grafted copolymers under ultrasound during polymerization of hydrophobic monomers in PVP aqueous solutions. The part of polystyrene and polyacrylate chains in copolymer macromolecules exceeds PVP part which is insoluble in benzene and toluene.

The results of physico-mechanical and sorptiondiffusion properties of the synthesized copolymers are represented in Table 1. 
Physico-mechanical and sorption-diffusion properties of the films based on synthesized copolymers

\begin{tabular}{|c|c|c|c|c|c|}
\hline Copolymer & $\begin{array}{c}\text { Water content, } \\
\%\end{array}$ & $\begin{array}{c}\text { Coefficient of water } \\
\text { permeability }\left(\mathrm{K} \cdot 10^{4}\right), \\
\mathrm{m}^{3} / \mathrm{m}^{2} \cdot \mathrm{h}\end{array}$ & $\begin{array}{c}\text { Coefficient of } \mathrm{NaCl} \text { penetration, } \\
\mathrm{mol} / \mathrm{m}^{2} \mathrm{~h}\end{array}$ & $\sigma_{t}, \mathrm{MPa}$ & $\varepsilon, \%$ \\
\hline $\begin{array}{c}\text { Poly(vinylpyrrolidone-grafted } \\
\text { styrene) }\end{array}$ & $\frac{3.1}{0.2^{*}}$ & $\frac{6.1}{0}$ & $\frac{54}{0}$ & $\frac{39}{41}$ & $\frac{9}{3}$ \\
\hline $\begin{array}{c}\text { Poly(vinylpyrrolidone-grafted } \\
\text { methylmethacrylate) }\end{array}$ & $\frac{4.2}{0.3^{* *}}$ & $\frac{9.3}{-}$ & $\frac{76}{-}$ & $\frac{54}{58}$ & $\frac{14}{4}$ \\
\hline
\end{tabular}

Notes: $\sigma_{t}-$ tensile strength; $\varepsilon$ - relative elongation at break; $*$ - for polystyrene; $* *$ - polymethylmethacrylate

The introduction of PVP chains provides copolymers by hydrophilic properties, permeability for water and electrolytes soluble in it and increases their elasticity. At the same time the copolymers strength stays sufficiently high that allows to recoMWend them for the production of various coatings and selectively penetrating membranes.

\section{Conclusions}

The obtained results confirm the possibility of hydrophobic vinyl monomers polymerization on the phase boundary with PVP aqueous solution under ultrasound. The main regularities of polymerization were investigated. The destruction of PVP macromolecules occurs under ultrasound and the formed macroradicals participate in grafted and block-copolymerization reactions. The formed copolymers (in contrast to homopolymers of hydrophobic monomers) acquire hydrophilic properties and permeability for water and electrolytes. Such new properties allow to use synthesized copolymers for the production of film coatings and selectively penetrating membranes.

\section{References}

[1] Pavlyuchenko V. and Ivanchev S.: Vysokomol. Soed., 2009, 51, 1075.

[2] Suberlyak O., Semenyuk N. and Skorokhoda V.: J. Appl. Chem., 2012, 85, 830.

[3] Radzhedran V.: Primenenie Ultrazvuka. Technosfera. Moskwa 2006.
[4] Selyakova V. and Kashevarova Yu.: Metody Analiza Acrylatov i Metacrylatov. Khimiya, Moskwa 1982.

[5] Dubyaga V., Perepechkin L. and Katalevskyi E.: Polymernye Membrany. Khimiya, Moskwa 1981.

[6] Mokryi E. and Starchevskyy V.: Ultrazvuk v Processah Okisleniya Organicheskykh Soedineniy. Vyschaya schkola, Lviv 1987.

[7] Suberlyak O., Levitskyi V., Skorokhoda V. and Godiy A.: Ukr. Khim. Zh., 1998, 64, 122.

[8] Suberlyak O., Levitskyi V. and Skorokhoda V.: Ukr. Polym. J., 1995, 4, 177.

[9] Chou H. and Stoffer J.: J. Appl. Polym. Sci., 2003, 72, 827.

\section{ОСОБЛИВОСТІ ОДЕРЖАННЯ ТА ВЛАСТИВОСТІ КОПОЛІМЕРІВ ПОЛІВІНІЛПІРОЛІДОНУ 3 ГІДРОФОБНИМИ ВІНІЛЬНИМИ МОНОМЕРАМИ}

Анотація. Досліджено полімеризацію гідрофобних вінільних мономерів у водних розчинах полівнілпіролідону під дією ультразвуку. Вивчено вплив ультразвуку на деструкиію водорозчинних полімерних матриць та запропоновано механізм реакиії одержання блок- та прищеплених кополімерів вінільних мономерів з полівінілпіролідоном. Синтезовано кополімери у вигляді плівок та досліджено їхні основні властивості, зокрема фізикомеханічні та сорбиійно-дифузійні.

Ключові слова: полівінілпіролідон, плівкові покриття, деструкиія, ультразвук, блокові кополімери, проникність. 
